\title{
A life cycle assessment of packaging options for contrast media delivery: comparing polymer bottle vs. glass bottle
}

\author{
Harnoor Dhaliwal • Martin Browne • William Flanagan • \\ Lise Laurin • Melissa Hamilton
}

Received: 11 October 2013 / Accepted: 25 August 2014 /Published online: 16 September 2014

(C) The Author(s) 2014. This article is published with open access at Springerlink.com

\begin{abstract}
Purpose This paper compares environmental impacts of two packaging options for contrast media offered by GE Healthcare: +PLUSPAK ${ }^{\mathrm{TM}}$ polymer bottle and traditional glass bottle. The study includes all relevant life cycle stages from manufacturing to use and final disposal of the bottles and includes evaluation of a variety of end-of-life disposal scenarios. The study was performed in accordance with the international standards ISO 14040/14044, and a third-party critical review was conducted.

Methods The functional unit is defined as the packaging of contrast media required to deliver one dose of $96 \mathrm{~mL}$ to a patient for an X-ray procedure. Primary data are from GE Healthcare and its suppliers; secondary data are from the ecoinvent database and the literature. A variety of end-of-life disposal scenarios are explored using both cutoff and marketbased allocation. Impact assessment includes human health (midpoint) and ecosystems and resources (end point) categories from $\mathrm{ReCiPe}(\mathrm{H})$ and cumulative energy demand. Sensitivity analyses include (1) bottle size, (2) secondary packaging, (3) manufacturing electricity, (4) glass recycled content, (5) scrap rate, (6) distribution transport, (7) contrast media, and (8) choice of impact assessment method.
\end{abstract}

Responsible editor: Hans-Jürgen Garvens

Electronic supplementary material The online version of this article (doi:10.1007/s11367-014-0795-1) contains supplementary material, which is available to authorized users.

H. Dhaliwal · L. Laurin · M. Hamilton

EarthShift LLC, 830 Taft Road, Huntington, VT 05462, USA

M. Browne

GE Healthcare, Nycoveien 1-2 Postboks 4220 Nydalen, 0401 Oslo, Norway

W. Flanagan $(\bowtie)$

GE Global Research, 1 Research Circle, Niskayuna, NY 12309, USA

e-mail: flanagan@ge.com
Uncertainty analysis is performed to determine how data quality affects the study conclusions.

Results and discussion This study indicates that the polymer bottle outperforms the glass bottle in every environmental impact category considered. Bottle components are the most significant contributors, and the vial body has the highest impacts among bottle components for both polymer and glass bottles. The polymer bottle exhibits lower impact in all impact categories considered regardless of the following: end-of-life treatment (using either cutoff or market-based allocation), bottle size, manufacturing electricity grid mix, glass recycled content, scrap rate, contrast media, distribution transport (air vs. ocean), and choice of impact assessment method. Secondary packaging can be a major contributor to impact. The polymer bottle has considerably lower impact compared to the glass bottle for all multi-pack configurations, but the comparison is less clear for single-pack configurations due to significantly higher packaging material used per functional dose, resulting in proportionally higher impacts in all impact categories.

Conclusions The lower impacts of the polymer bottle for this packaging application can be attributed to lower material and manufacturing impacts, lower distribution impacts, and lower end-of-life disposal impacts. The results of this study suggest that using polymer rather than glass bottles provides a means by which to lower environmental impact of contrast media packaging.

Keywords Glass · Hospital $\cdot$ Life cycle assessment · Packaging $\cdot$ Polymer $\cdot$ Waste

\section{Introduction}

The environmental impacts of plastic and glass bottles have been examined in a number of studies. Belboom et al. (2011) 
assessed polymer vs. glass vials for injectable drug primary packaging and concluded that polymer vials show environmental benefit due to lower manufacturing impacts, a simpler filling step, and lower transport impacts due to lower weight. Humbert et al. (2009) conducted a comparison of glass jars and plastic (polypropylene) pots used for baby food packaging, concluding that the plastic pots show a "small but significant" reduction in environmental burden compared to the glass jars due to factors such as lower manufacturing impacts, lower transportation impacts due to lighter weight, and lower end-oflife disposal impacts. Other studies on packaging materials yield a variety of results (Frees and Weidema 1998; Franklin Associates 2009; Lee and Xu 2005; Owens-Illinois 2010). Note that these studies do not necessarily reflect the inherent environmental benefit of one packaging material type over another since the results are specific to each packaging application and to the goal and scope of each particular study (including differences in assumptions regarding recycling rates).

The present LCA study compares the environmental impacts of two primary packaging options for contrast media used for diagnostic imaging procedures: a traditional glass bottle and the +PLUSPAK ${ }^{\mathrm{TM}}$ polymer (polypropylene) bottle, both manufactured by GE Healthcare. The study was performed to understand the environmental impacts and key drivers of impact for each packaging option and comprehensively explores end-of-life disposal scenarios using both cutoff and market-based allocation approaches. A comprehensive approach to end-of-life is important when products are globally distributed and face a variety of regional disposal regulations and practices. Market-based system expansion approaches are increasingly being used to deal with multifunctionality in recycling (Manfredi et al. 2012).

This study follows the guidelines outlined by the international standards ISO 14040 and ISO 14044 (ISO 2006a, 2006b) including third-party critical review as the study involves comparative assertions intended for public disclosure. Key findings are summarized; additional study details are provided as Electronic Supplementary Material.

\section{Methods}

\subsection{Goal and scope}

The goal of this study is to assess and compare the life cycle environmental impacts associated with polymer $\left(+P L U S P A K^{\mathrm{TM}}\right)$ and glass bottles used for delivering contrast media for X-ray procedures. A functional unit is defined to ensure that any comparisons are made on a functionally equivalent basis; in this study, the functional unit is defined as the packaging of contrast media required to deliver one dose of $96 \mathrm{~mL}$ to a patient for an X-ray procedure. The study examines both bottle types, from cradle-to-grave, by assessing the impacts associated with raw material extraction, production, distribution, use, and disposal. Several bottle sizes are assessed including 50,100, 200, and $500 \mathrm{~mL}$. The 100-mL bottle size with a dose of $96 \mathrm{~mL}$ is selected as the primary basis of comparison.

\subsection{Life cycle inventory analysis}

The +PLUSPAK ${ }^{\mathrm{TM}}$ polymer bottle consists of a pharmaceutical-grade polypropylene vial, rubber stopper, and polypropylene cap (all virgin materials); the glass bottle consists of a glass vial (containing 10-30\% glass cullet), rubber stopper, and a crimp seal made of aluminum and polypropylene.

Primary data and product information (including material types and quantities, manufacturing processes and associated parameters, supply chain, and distribution transport logistics including breakage and product loss) are provided by GE Healthcare and its suppliers. Secondary data (including cradle-to-gate materials extraction and refining and end-oflife treatment) are obtained from the ecoinvent life cycle inventory database (ecoinvent Centre 2010) and from the literature. Process data for autoclaving of the glass bottles at end-of-life are purchased (Environmental Clarity 2012). All material, energy, and environmental flows are quantified for each step in the product life cycle in accordance with the functional unit definition. Life cycle inventories for supply chain, assembly and filling, transport, and use are described in the Electronic Supplementary Material along with discussion of cutoff criteria, excluded data, and assumptions.

End-of-life The use and disposal of GE Healthcare's contrast media packaging takes place in hospitals across the globe. This study examines a wide range of end-of-life scenarios because of the various treatment methods used in different countries as well as within countries.

The default end-of-life treatments in this study are based on the most likely disposal methods for plastic and glass contrast media bottles in the USA. The polymer bottles are likely to be treated as municipal waste (Ed Krisiunas, President, WNWN International, personal communication, 2012), and the study assumes an average split of $80 \%$ landfill and $20 \%$ incineration (US EPA 2012). The glass bottles are likely to be disposed of in a sharps container (Morrison and Odle 2007; Blackburn and Hawley 2006) and would therefore be treated by autoclaving and landfilling.

Additional treatment scenarios are considered (Table 1). In the European Union, most types of waste are stratified by the European Waste Catalog (European Waste Catalogue and Hazardous Waste List 2002). Some of the likely treatments for the sharps waste and other potentially infectious waste include (1) autoclaving and incineration; (2) incineration; and (3) pre-shred, autoclave, and incineration. 
Table 1 End-of-life disposal scenarios for $+P L U S P A K^{\mathrm{TM}}$ and glass bottles using either cutoff or market-based allocation approaches

\section{+ PLUSPAK ${ }^{\mathrm{TM}}$ waste disposal scenarios}

Cutoff allocation

Municipal waste

$80 \%$ to landfill; $20 \%$ to municipal incineration.

Autoclave and incineration

All materials autoclaved and then sent to municipal incineration. Incineration

All materials sent to municipal incineration.

Pre-shred, autoclave, and incineration

All materials shredded, autoclaved, and sent to municipal incineration. Recycle

Polypropylene to recycling (no impact or benefit). All other materials $80 \%$ landfill $/ 20 \%$ municipal incineration.

Glass bottle waste disposal scenarios

Cutoff allocation

Autoclave and landfill

All materials autoclaved and then landfilled. Allocated portion of sharps container (polypropylene) included in disposal of glass and aluminum materials.

Autoclave and incineration

All materials autoclaved and then sent to municipal incineration. Allocated portion of sharps container (polypropylene) included in disposal of glass and aluminum materials.

Incineration

All materials sent to municipal incineration.

Pre-shred, autoclave, and incineration

All materials shredded, autoclaved, and sent to municipal incineration. Allocated portion of sharps container (polypropylene) included in disposal of glass and aluminum materials.

Recycle

Glass to recycling (no impact or benefit). All other materials to $80 \%$ landfill/20\% municipal incineration.
Market-based allocation

Municipal waste

Incineration includes credit for electricity and heat generation as avoided burden:

Polypropylene: $3.74 \mathrm{MJ}$ electricity $/ \mathrm{kg} ; 7.54 \mathrm{MJ}$ heat $/ \mathrm{kg}$

Rubber: $3.02 \mathrm{MJ}$ electricity/kg; $6.11 \mathrm{MJ}$ heat $/ \mathrm{kg}$

Autoclave and incineration

Incineration includes credit for electricity and heat generation as above.

Incineration (waste-to-energy)

Incineration includes credit for electricity and heat generation as above.

Pre-shred, autoclave, and incineration

Incineration includes credit for electricity and heat generation as above. Recycle

Polypropylene to recycling (transport and shredding impacts included). Full credit for virgin polypropylene as avoided burden. All other materials $80 \%$ landfill $/ 20 \%$ municipal incineration.

Market-based allocation

Autoclave and landfill

No difference from cutoff method.

Autoclave and incineration

Incineration includes credit for electricity and heat generation from rubber and polypropylene as above, but not from glass or aluminum.

Incineration (waste-to-energy)

Incineration includes credit for electricity and heat generation from rubber and polypropylene as above, but not from glass or aluminum.

Pre-shred, autoclave, and incineration

Incineration includes credit for electricity and heat generation from rubber and polypropylene as above, but not from glass or aluminum.

Recycle

$68 \%$ of glass is recycled, with autoclaving and cullet sorting impacts included. Remaining glass is sent to municipal incineration. Other materials sent to $80 \%$ landfill $/ 20 \%$ incineration.
The study also considers recycling of materials at end-of-life. Two approaches are used to allocate the environmental impacts associated with recycling. The cutoff approach (Frischknecht 2010; Frischknecht et al. 2007) assigns environmental burdens of material production (raw material extraction, processing, etc.) to the first life of a material and assigns material refurbishment impacts (collection and scrap processing) to its second life. The sensitivity of the results to choice of allocation method is tested by using the market-based approach for system expansion (Weidema 2003), in which the level of material utilization in the recycled materials market determines how the environmental burdens and benefits of recycling are allocated.

The cutoff allocation approach is also applied to landfill (no credit for landfill gas, if any) and incineration (no credit for heat recovery or electricity generation, if any). The market-based allocation approach is applied to incineration of the bottles by applying a credit for the heat and electricity generated.

\subsection{Life cycle impact assessment}

Since this study is directed toward health-care professionals, human health impacts are of primary importance. The healthcare industry is also keenly aware of energy and solid waste issues. To address these perspectives, this study uses human health midpoint impact categories and ecosystem quality and resources end point damage categories from the internationally accepted method ReCiPe (H) (Goedkoop et al. 2009). The climate change impact category within the ReCiPe Midpoint 
(H) method includes all greenhouse gases specified in the Kyoto Protocol using global warming potentials from the IPCC Fourth Assessment Report with a 100-year time horizon (IPCC 2007). The cumulative energy demand (CED) method (Jungbluth and Frischknecht 2010) is used to evaluate energy demand associated with a product's life cycle. The IMPACT $2002+$ (Jolliet et al. 2003) and USEtox (Rosenbaum et al. 2008) methods are used to assess the sensitivity of the results to choice of impact assessment methodology.

\subsection{Sensitivity and uncertainty analyses}

Sensitivity analyses are performed to assess the effect of different bottle sizes $(50,100,200,500 \mathrm{~mL})$, electricity grids (Europe, China, US), glass bottle recycled content (10-60\% cullet), polymer scrap rate (5-50\%), mode of distribution transport (air vs. ocean freight), different contrast media solutions (X-ray vs. MRI diagnostic agents), secondary packaging and shipping container (single-pack vs. multi-pack), and choice of impact assessment method (ReCiPe H vs. IMPACT $2002+$ vs. USEtox).

Uncertainty analysis is performed to understand how data quality affects the reliability and robustness of the study results for the comparison of the $100-\mathrm{mL}$ glass and + PLUSPAK ${ }^{\mathrm{TM}}$ polymer bottles using the default end-of-life treatments. Flows and parameters within the model are input as probabilistic values, typically using lognormal distributions based on the pedigree matrix approach (Weidema and Wesnæs 1996). Monte Carlo simulations are performed (1,000 runs), and a distribution is plotted indicating the percentage of runs in which one bottle type exhibits lower impact compared to the other bottle type in each impact category.

\section{Results and discussion}

The results reported here focus on comparison of the 100-mL glass and + PLUSPAK ${ }^{\mathrm{TM}}$ polymer bottles for delivering one dose $(96 \mathrm{~mL})$ of contrast media for an X-ray procedure. The comparative analysis indicates that, based on the data used and the assumptions made in this study, the polymer bottle has considerably lower environmental impact compared to the glass bottle for all of the impact categories considered (Fig. 1): lower greenhouse gas emissions ( $46 \%$ of emissions compared to glass), requires less cumulative energy (55\%), lower impact on ecosystems (39\%), lower impact on resources (59\%), and lower impacts in all other categories that are considered (ranging from 24 to $43 \%$ ).

Contribution analysis (Fig. 1) indicates that vial manufacturing is the most significant contributor for either bottle type. The bottle components (vial body, cap, crimp seal, and stopper) are the most significant contributors, and the vial body has the highest impacts among the bottle components for all impact categories considered (Table 2). Secondary packaging - meaning the outer box and dividers - and shipping container also contribute to impact. Raw material transport, autoclaving during manufacturing, quality control (QC) rejects, broken and frozen bottles, lost contrast media, and incubation just prior to use are all minor contributors relative to other impacts $(<1.3 \%$ in all impact categories).

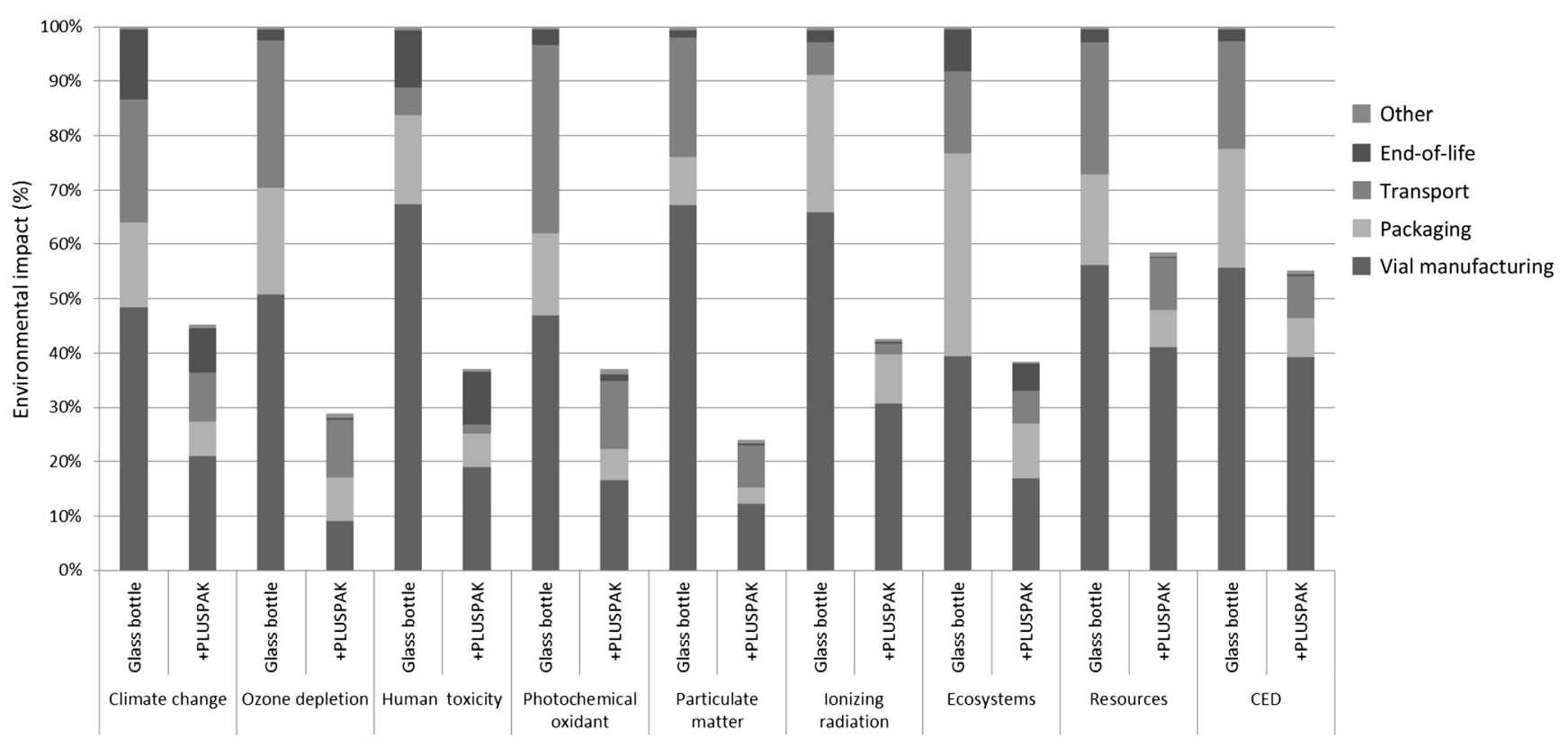

Fig. 1 Life cycle comparison of 100-mL + PLUSPAK ${ }^{\mathrm{TM}}$ and glass bottles for X-ray contrast media. Vial manufacturing includes vial body, cap, stopper, crimp, depyrogenation, and autoclaving. Packaging includes

secondary packaging and shipping container. Transport includes raw material transport and distribution transport. The Other category includes QC rejects, broken and frozen bottles, lost contrast media, and incubation 


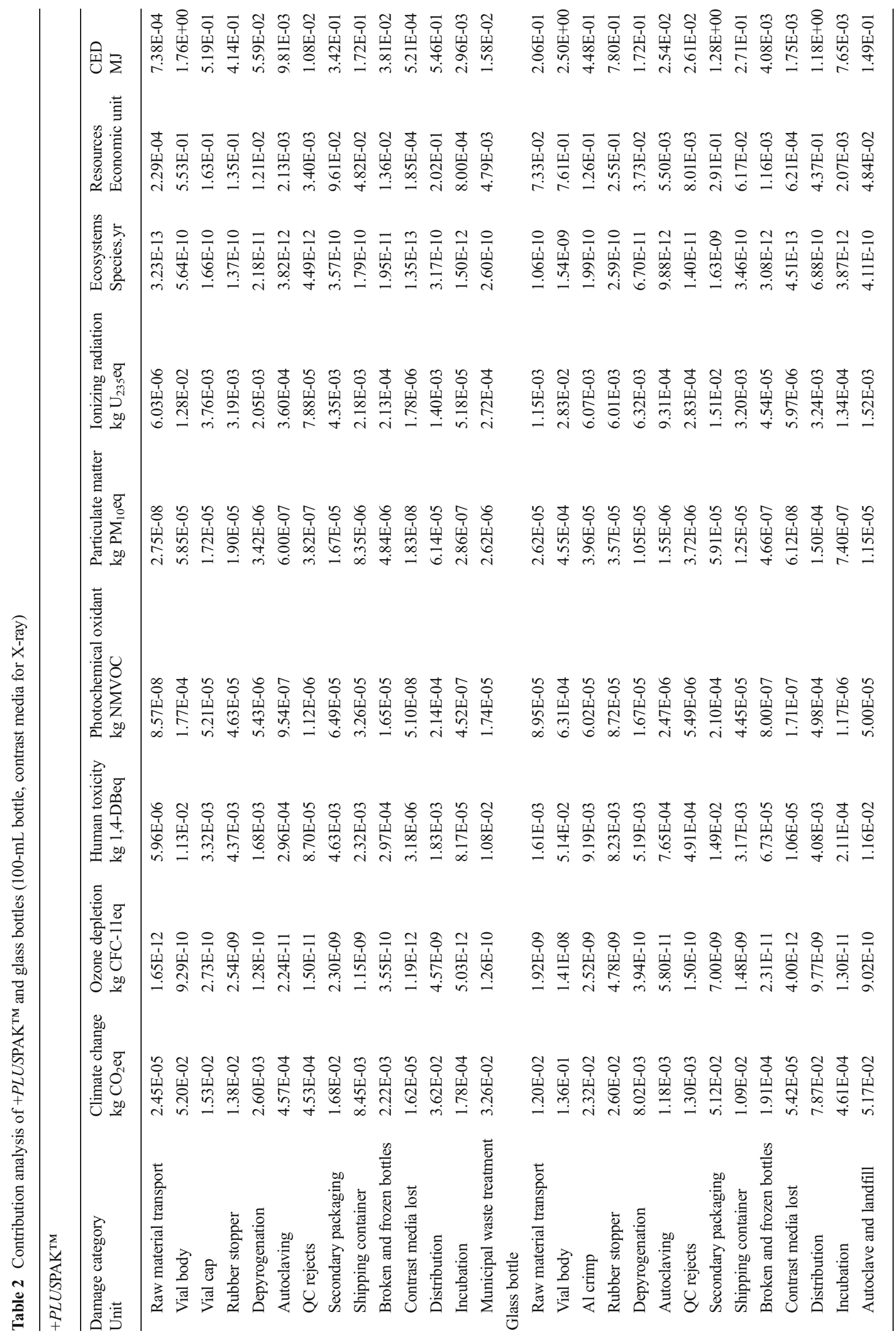


Sensitivity analyses show that only the secondary packaging and shipping container have the potential to affect the comparative conclusions. For both bottle types, multi-pack packaging configurations have considerably less impact than single-pack configurations since less packaging materials are required per functional dose (Table 3). When multi-pack secondary packaging configurations are used, the polymer bottle exhibits lower environmental impacts compared to the glass bottle in all impact categories considered. When single-pack secondary packaging configurations are used, the polymer bottle exhibits lower impacts in some categories (particulate matter, ecosystems), but no clear benefit in other categories.

The study results indicate that the polymer bottle is environmentally favorable compared to the glass bottle regardless of the end-of-life disposal method for either bottle type or whether cutoff or market-based allocation is used (Table 4). The polymer bottle life cycle impacts range from 24 to $60 \%$ (using cutoff allocation) or 20-57\% (using market-based allocation) of the default glass bottle impacts depending on impact category and end-of-life treatment.

The study compares different bottle sizes on a functionally equivalent "per dose" basis - two $50-\mathrm{mL}$ bottles, one 100-mL bottle, half a $200-\mathrm{mL}$ bottle, and one fifth of a $500-\mathrm{mL}$ bottle. The polymer bottle exhibits lower environmental impact compared to the glass bottle for each bottle size (see Fig. S4 in the Electronic Supplementary Material). The $500-\mathrm{mL}$ bottle has the lowest impacts per dose, and the $50-\mathrm{mL}$ bottle has the highest impacts per dose for both bottle types. This can be attributed to the need for less bottle material and packaging (per dose) for the larger bottle sizes.

Sensitivity to air freight is examined by replacing all of the air transport with ocean freight for both bottle types. This change can reduce impacts by up to $30 \%$ for the polymer bottle and up to $20 \%$ for the glass bottle, but the polymer bottle still exhibits lower environmental impact compared to glass (see Table S4 in the Electronic Supplementary Material). Other sensitivity analyses results are shown in detail in section 2 of the Electronic Supplementary Material.

The Monte Carlo uncertainty analysis indicates that the polymer bottle has significantly lower environmental impact compared to glass in all impact categories considered. The differences are greater than zero in all 1,000 runs, and the distributions of the differences do not contain zero, indicating that the differences between the polymer and glass bottle are in fact significant. The results calculated from a Wilcoxon signed-rank test (Bauer 1972; Hollander and Wolfe 1999) confirm that the differences between the two bottle types are significant at the $95 \%$ confidence level.

\section{Conclusions}

By analyzing the + PLUSPAK ${ }^{\mathrm{TM}}$ (polymer) and glass bottles, this study provides useful insight regarding the comparative

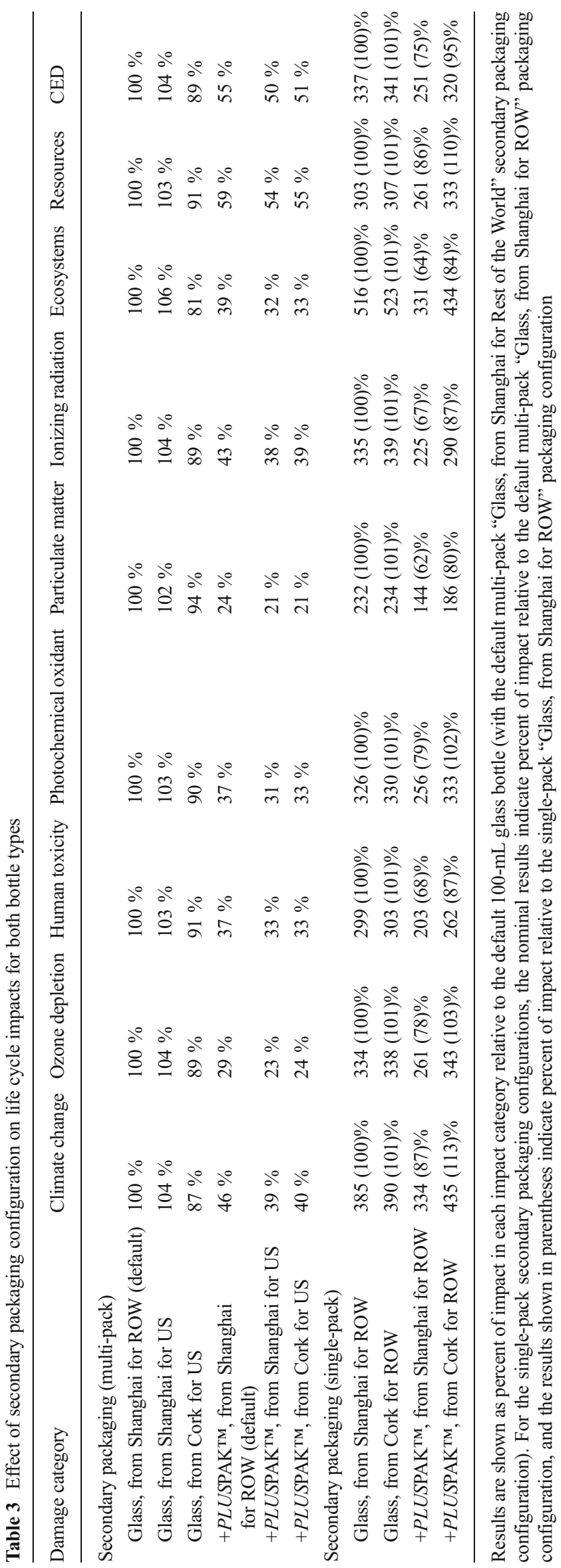




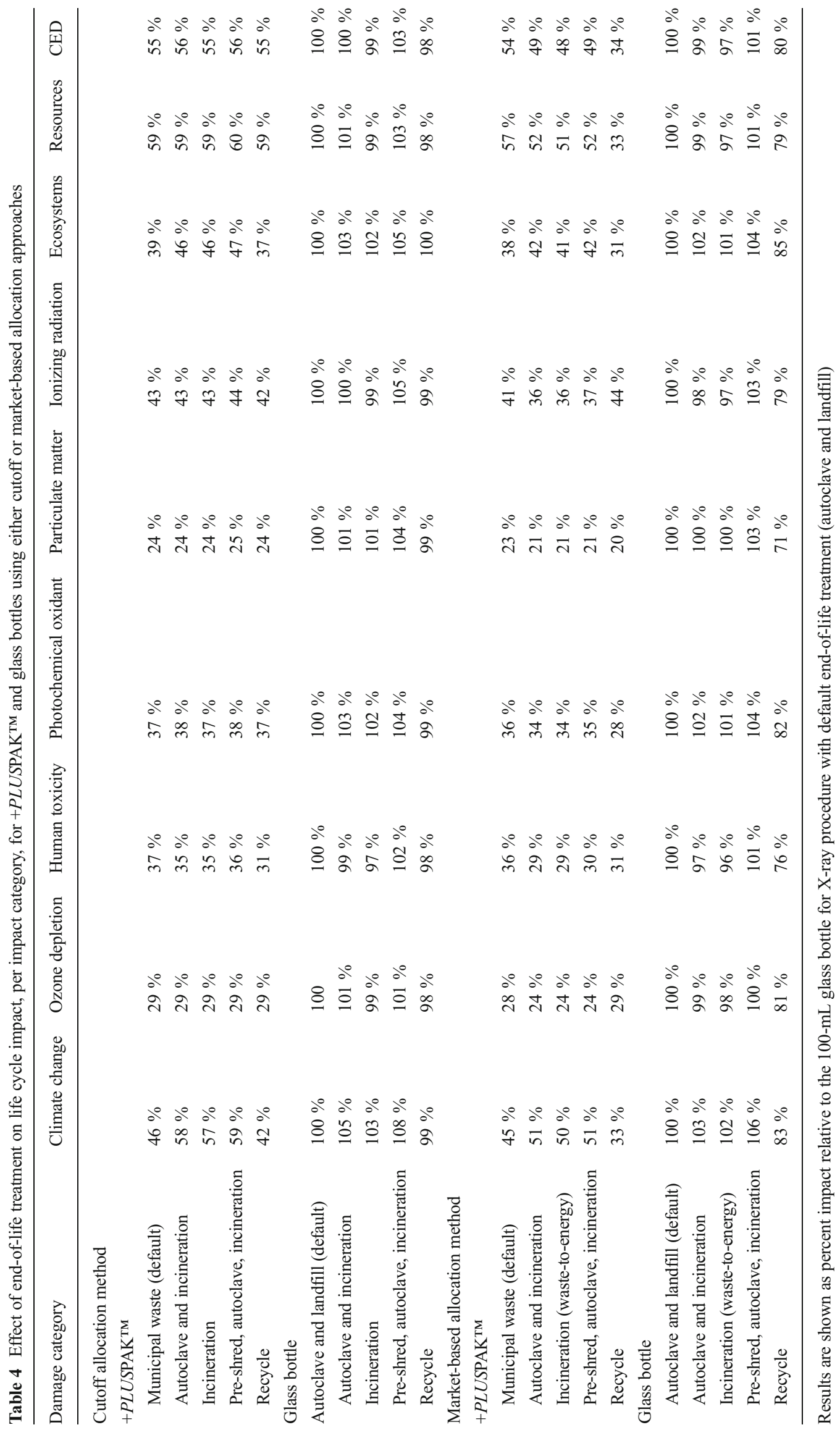


environmental impacts and indicates where the largest impacts are occurring for each bottle type. Based on the assumptions, data, and methods used in this study, the polymer bottle outperforms comparably sized glass bottles by a considerable margin in every environmental impact category that is considered. The lower life cycle impacts of the polymer bottle can be generally attributed to the following: (1) lower material and manufacturing impacts partly due to its lower mass, (2) lower distribution impacts due to its lower mass, and (3) lower endof-life disposal impacts due to lower disposal impacts and lower mass. Secondary packaging is an important contributor to impact relative to the polymer and glass bottles. While polymer bottles exhibit considerably less environmental impact compared to the glass bottle for all multi-pack shipping configurations, the environmental benefit of the polymer bottle is less clear when single-pack shipping configurations are used (due to significantly higher quantities of packaging materials used per functional dose for both bottle types).

The study results suggest that lower environmental impact of contrast media packaging can be accomplished by the following: (1) using polymer rather than glass bottles, (2) using larger bottle sizes where feasible (lower impact per functional unit), (3) using material-efficient shipping configurations (multi-pack rather than single-pack), (4) reducing the proportion of distribution via air freight, and (5) encouraging recycling as an end-of-life treatment option (where available).

Acknowledgments The authors would like to thank Paritosh Dhawale, Akshay Yeshokumar, Torunn Sveen, Siv Borling Winge, Edit Anderson, Celine Anoufa, Cecile Gonzaga, Caroline Widlund, and Lynn Wilks from GE Healthcare for their support of and participation in this study; Matthew Pietrzykowski from GE Global Research for contributions to the statistical analyses; and the members of the critical review panel, Joep Meijer (The Right Environment, Ltd.), Dr. Susan Selke (Professor, School of Packaging, Michigan State University), and Ed Krisiunas MT(ASCP) MPH (President, WNWN International), for their input and critiques that greatly improved the quality and robustness of this study.

Open Access This article is distributed under the terms of the Creative Commons Attribution License which permits any use, distribution, and reproduction in any medium, provided the original author(s) and the source are credited.

\section{References}

Bauer DF (1972) Constructing confidence sets using rank statistics. J Am Statist Assoc 67(339):687-690

Belboom S, Renzoni R, Verjans B, Léonard A, Germain A (2011) A life cycle assessment of injectable drug primary packaging: comparing the traditional process in glass vials with the closed vial technology (polymer vials). Int J Life Cycle Assess 16(2):159-167
Blackburn J, Hawley R (2006) Contrast packaging: implications for cost and employee safety. Available from http://md.gehealthcare.com/GE Contrast_Packaging_Article_Reprint.pdf. Accessed April 1, 2012

ecoinvent Centre (2010) ecoinvent data v2.2. ecoinvent reports No. 1-25, Swiss Centre for Life Cycle Inventories, Dübendorf, available from: http://www.ecoinvent.org

Environmental Clarity (2012). Available from www. environmentalclarity.com

European Waste Catalogue and Hazardous Waste List (2002) Environmental Protection Agency, PO Box 3000, Johnstown Castle Estate, County Wexford, Ireland. Available from http:// www.epa.ie

Franklin Associates (2009) Life cycle inventory of three single-serving soft drink containers. Available from http://www.petresin.org/pdf/ FranklinLCISodaContainers2009.pdf. Accessed May 142013

Frees N, Weidema B (1998) Life cycle assessment of packaging systems for beer and soft drinks. Energy and transport scenarios. Technical report 7, Ministry of Environment and Energy, Danish Environmental Protection Agency (Environmental Project 406)

Frischknecht R (2010) LCI modelling approaches applied on recycling of materials in view of environmental sustainability, risk perception and eco-efficiency. Int $\mathrm{J}$ Life Cycle Assess 15(7):666-671

Frischknecht R, Jungbluth N, Althaus H, Doka G, Dones R, Heck T, Hellweg S, Hischier R, Nemecek T, Rebitzer G, Spielmann M, Wernet G, (2007) Overview and methodology, ecoinvent report No. 1, Swiss Centre for Life Cycle Inventories, Dübendorf, $\mathrm{CH}$. Available from http://www.ecoinvent.org

Goedkoop M, Heijungs R, Huijbregts M, De Schryver A, Struijs J, van Zelm R (2009) ReCiPe 2008: A life cycle impact assessment method which comprises harmonised category indicators at the midpoint and the endpoint level, VROM-Ruimte en Milieu, Ministerie van Volkshuisvesting, Ruimtelijke Ordening en Milieubeheer. Available from http://www.lcia-recipe.net

Hollander M, Wolfe DA (1999) Nonparametric statistical methods. John Wiley \& Sons, New York

Humbert S, Rossi V, Margni M, Jolliet O, Loerincik Y (2009) Life cycle assessment of two baby food packaging alternatives: glass jars vs. plastic pots. Int J Life Cycle Assess 14(2):95-106

IPCC (2007) Climate change 2007: the physical science basis. Contribution of Working Group I to the Fourth Assessment Report of the Intergovernmental Panel on Climate Change. Solomon S, Qin $\mathrm{D}$, Manning $\mathrm{M}$ et al (eds). Cambridge University Press, Cambridge, UK, and New York, USA

ISO (2006a) ISO 14040 - Environmental management-life cycle assessment - principles and framework, International Organisation for Standardization

ISO (2006b) ISO 14044 - Environmental management-life cycle assessment-requirements and guidelines, International Organisation for Standardization

Jolliet O, Margni M, Charles R, Humbert S, Payet J, Rebitzer G, Rosenbaum R (2003) IMPACT 2002+: a new life cycle impact assessment methodology. Int J Life Cycle Assess 8(6):324-330

Jungbluth N, Frischknecht R (2010) Implementation of life cycle impact assessment methods - chapter 2: cumulative energy demand, Ecoinvent report No. 3, Swiss Centre for LCI, Dübendorf, CH. Available from $\mathrm{http} / / / \mathrm{www}$.ecoinvent.org

Lee S, Xu X (2005) Design for the environment: life cycle assessment and sustainable packaging issues. Int J Environ Tech Manage 5(1): 14-41

Manfredi S, Allacker K, Chomkhamsri K, Pelletier N, Maia de Souze D (2012) Product Environmental Footprint (PEF) Guide, European Commission, Joint Research Centre. Available from http://ec.europa. eu/environment/eussd/pdf/footprint/PEF\%20methodology $\% 20$ final $\%$ 20draft.pdf 
Morrison G, Odle TG (2007) Contrast media handling. Radiol Technol 79(1):86-90

Owens-Illinois (2010) The complete life cycle assessment. Available from http://www.o-i.com/uploadedFiles/Content/Stacked_Content/ OI LCA 031010.pdf. Accessed June 252012

Rosenbaum RK, Bachmann TM, Gold LS, Huijbregts MA, Jolliet O, Juraske R, Koehler A, Larsen HF, MacLeod M, Margni M (2008) USEtox - the UNEP-SETAC toxicity model: recommended characterisation factors for human toxicity and freshwater ecotoxicity in life cycle impact assessment. Int $\mathrm{J}$ Life Cycle Assess 13(7):532-546
US EPA (2012) Municipal solid waste (MSW) in the United States: facts and figures. Available from http:/www.epa.gov/osw/nonhaz/ municipal/msw99.htm. Accessed August 142012

Weidema B, (2003) Market information in life cycle assessment, Danish Ministry of the Environment, Danish Environmental Protection Agency (Environmental Project 863). Available from http://www2. mst.dk/Udgiv/publications/2003/87-7972-991-6/pdf/87-7972-9924.pdf. Accessed August 142012

Weidema BP, Wesnæs MS (1996) Data quality management for life cycle inventories - an example of using data quality indicators. J Clean Prod 4(3):167-174 